\title{
Design and Implementation of Offline Distance Learning System in Teaching Construction Cost Engineering
}

\author{
http://dx.doi.org/10.3991/ijet.v11i07.5794 \\ Yuqiao Yang, Kanhua Yu \\ Chang'an University, Xi'an, Shanxi, China
}

\begin{abstract}
This paper introduces current situation and defects of distance teaching platform and puts forward a design scheme to construct a distance teaching platform under the support of internet technology. The system owns diversified functions such as learning mode conversion, online learning and examination, and implements "low-flow" technology. Occupancy rate of such technology for network bandwidth is small in the operation process. Under the conditions of unstable network speed or slow network speed, it can operate fluently to make sure routine teaching and examination can be conducted normally. The application result of this system in Construction Cost Engineering shows that this system plays a significant role in improving the teaching quality of this course. Hence, it is feasible to apply the learning system in other courses.
\end{abstract}

Index Terms-distance learning system, Construction Cost Engineering, teaching application, offline

\section{INTRODUCTION}

Distance learning system, also called distance education training system, is a modern education platform based on internet platform. It can implements online distance education. Generally, distance learning system includes online learning and examination management system, courseware making and releasing system, virtual classroom system and server etc. besides, the teaching functions that distance learning system provides are also diversified [1]. Compared with traditional classroom teaching mode, the teaching modes of distance learning system richer, and its teaching convenience is most outstanding. Meanwhile, its teaching resources are very thorough. Therefore, distance learning system is increasingly introduced in college course teaching and examination [2]. Rao and Celeste established a distance learning platform in teaching ophthalmology. They adopted random intervention method to collect the disease data of 16 ophthalmic patients and submitted the data to distance education platform. Students learned through the distance education platform. The result indicates that the performance of students learning through distance teaching platform improves significantly [3]. Sowan and Jenkins prove the possibility that students are educated with limited technological resources. The participants included all college nursing students who were admitted to a distance and a hybrid section of communication skills course provided by a School of Nursing in Jordan. The result shows that the students learning through distance teaching system generally improves their satisfaction [4]. Basioudis et al. applied distance teaching platform in teaching accounting specialty, and investigated students' perception of design features involved in an "off the shelf" Learning Management System (LMS) in teaching college students. The result indicates that when distance teaching is applied, the application of lecture notes, announcement/ discussion board and other LMS tools can boost students' learning motivation [5].

The above research results are rich and offer abundant references for promotion and application of distance learning system. However, the application of distance learning system also has certain limitations. More importantly, it must be based on network platform to operate [6-7]. If the network is unstable or the network speed cannot reach the requirement of system, the functions of system will be restricted. This means the functions of distance learning system still remains improving. The innovations of this paper are as follows: "low-flow" distance learning system is designed and implemented. In system operation process, its occupancy rate for network bandwidth is very smack. Under the conditions of unstable network speed or slow network speed, it can operate fluently to make sure routine teaching and examination can be conducted normally.

Based on the above thought, this paper puts particular emphasis on the following contents: Firstly, overview of distance learning system. This paper mainly explores "low-flow" distance system design, including overall system analysis, system scheme and system module composition etc. On this basis, this paper also investigates the feasibility of applying this distance learning system in teaching Construction Cost Engineering. Secondly, teaching experiment analysis. Experiment teaching and mathematical statistics are used to test the teaching effect of "low-flow" teaching system in Construction Cost Engineering.

\section{OVERVIEW Of Distance LEARNING SySTEM}

\section{A. Overall system analysis}

The distance mathematical statistics is based on B/S architecture and includes two parts: student client and teacher service terminal. In actual lesson or examination process, students log in client program and link teacher service terminal through internet for online learning and examination. Figure 1 and figure 2 show overall frame and teaching module of distance learning system.

As shown in the below figure, overall frame of distance learning system focuses on internet. In other words, teachers and students can communicate online via internet. Besides, the system introduces "low-flow" technology and 


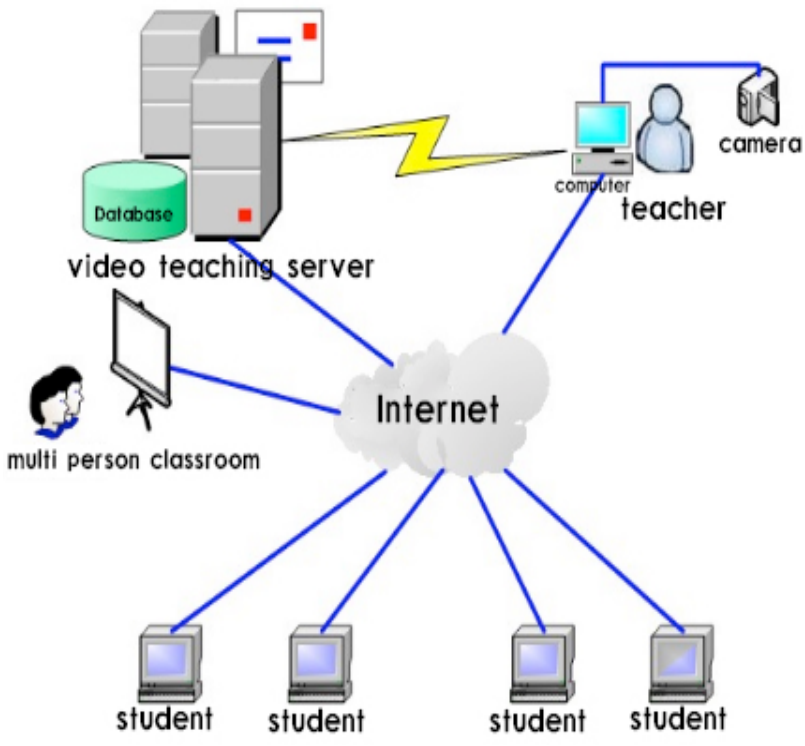

Figure 1. Overall frame diagram of distance learning system

thus can make sure it operates normally under the conditions of unstable network or low network speed. This also becomes an innovation of this platform.

\section{B. System design scheme}

Firstly, acquisition of teaching scene information. In distance teaching system, microphone recording and video recording devices can be used to capture on-spot teaching information and transmit signals between student client and teacher service terminal.

Secondly, compressing of teaching audio/video signal. When distance learning system operates, teaching audio/video signal is an important medium to implement teaching. In addition, to guarantee effective transmission of audio/video signal, it is required to compress the signal. Thus, it is very necessary to design the module to effectively filter interference signal and reserve real teaching signal.

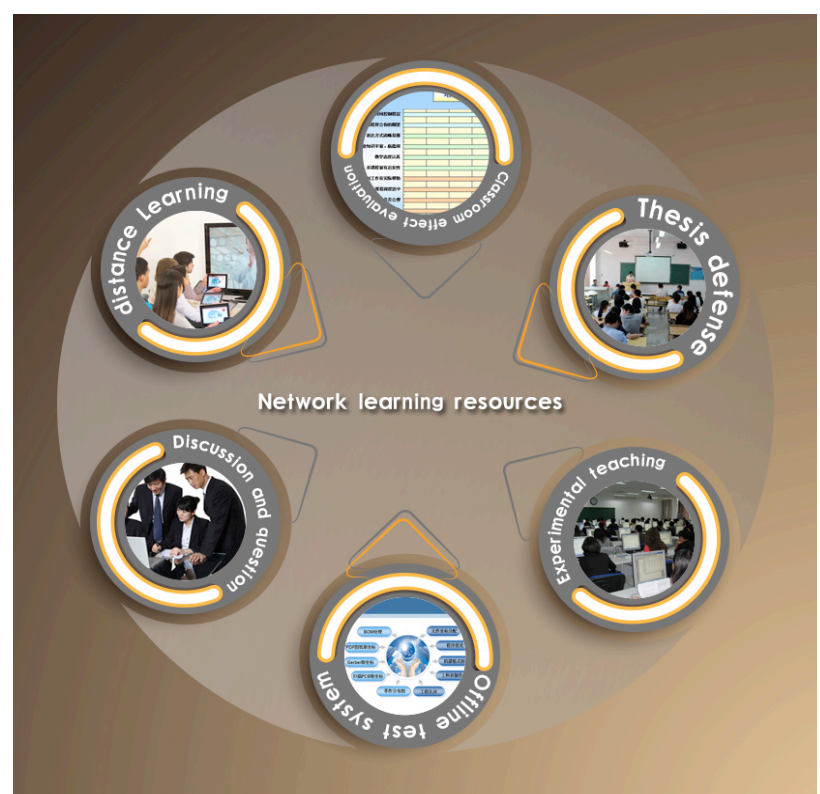

Figure 2. Composition of teaching module of distance learning system

Thirdly, network signal detection and feedback processing. To make the distance learning system test the online bandwidth and then to choose different working modes according to bandwidth, it is necessary to integrate network signal detection and feedback processing module in system design. With this module, once the system starts up, it can immediately test online bandwidth and determine learning mode according to bandwidth.

\section{System module composition}

Based on the above design thought, the distance learning system mainly includes 2 large modules and 8 small modules which consist of overall informatization layout of the system according to the architecture of "master-slave mode". In specific work, each module focuses on the chapters of Construction Cost Engineering for structural function design so as to highlight functions and practicability of the whole system. Figure 3 shows module structure diagram of distance learning system.

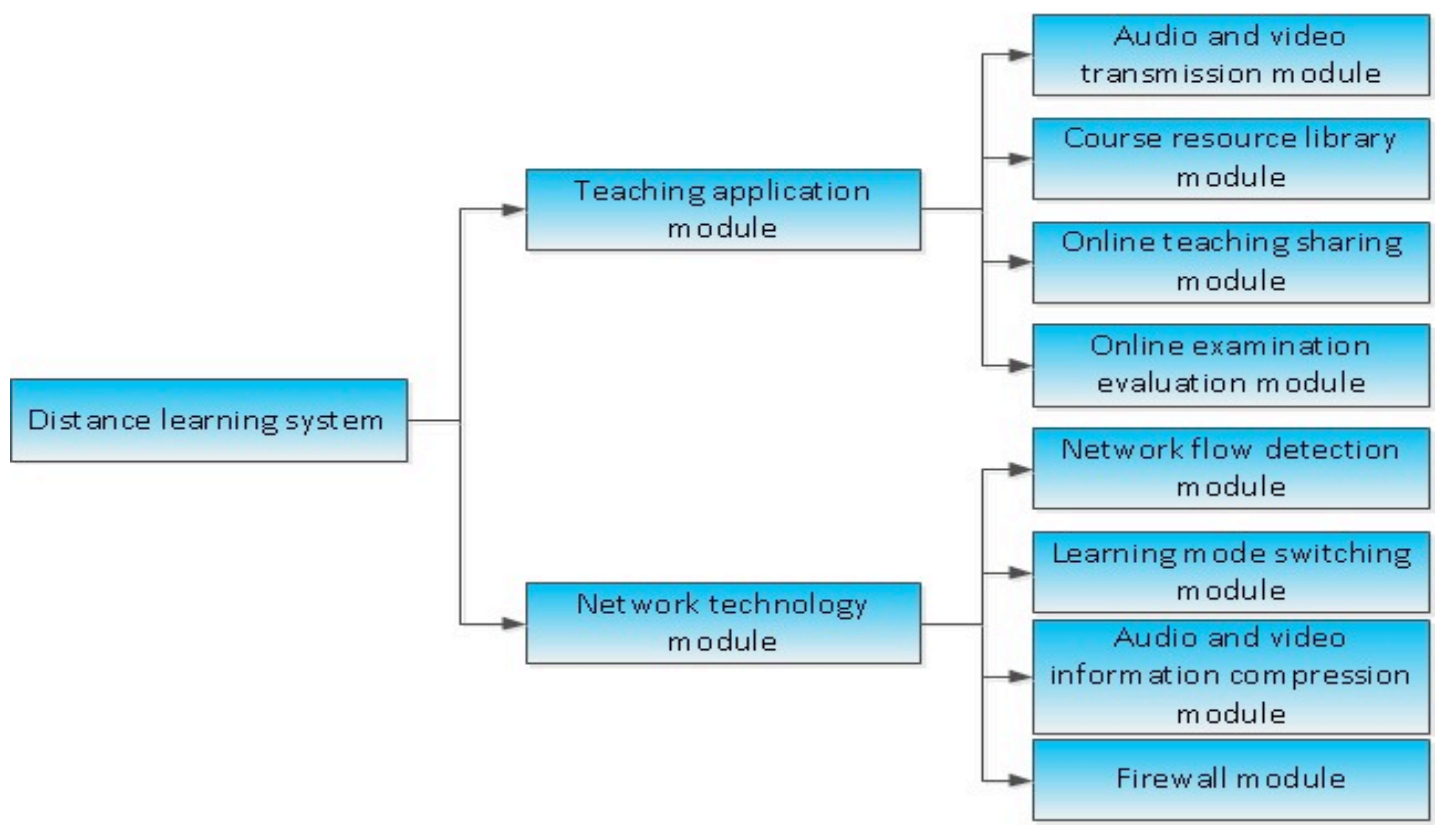

Figure 3. Module composition diagram of distance learning system 
In accordance with the above figure, the distance learning system owns numerous modules, mainly including teaching application and network technology modules. Each large module involves 4 sub-modules. Teaching application module includes such functional modules as audio/video transmission, course resource library, online learning and online examination, while network technology module is mainly composed of such modules as network flow detection, learning mode conversion, audio/video signal compressing and emergency handling for network disconnection.

The most outstanding feature of this distance learning system is that, it can detect network bandwidth in real time when the system operates, and automatically switches the learning mode according to detection result. For example, when a user logs in the system, the system will detect network bandwidth automatically. If real-time bandwidth is lower than the critical value of network speed required by system learning or examination, the system will automatically enter "offline learning mode" and download course learning program package for the user. After the course learning program package is installed, the user automatically enters learning login interface for learning. If the bandwidth can meet online learning requirement, the system will automatically enter "online learning mode, and the user can carry out online independent learning. Under the help of network detection and independent choice of system, even if current network environment is poor, the user can receive learning experience, without the influence on normal distance learning.

\section{TEACHING EXPERIMENT ANALYSIS}

\section{A. Teaching objects}

The students in Class 3 and Class 4 of 2013 architectural engineering specialty were chosen as the objects, and the number of students is 50 in total. The students in two classes have no significant statistical difference $(\mathrm{P}<0.05)$ in terms of age, gender and learning ability. In the specific teaching experiment, Class 3 served as the control group, and Class 4 served as the experimental class.

\section{B. Teaching design}

In the specific teaching, Construction Cost Engineering was selected as the teaching content. There were 48 class hours for this course. The course was composed of theoretical teaching and practical teaching modules. To highlight the teaching value of distance learning system, distance learning system was applied for the experimental class, and traditional teaching method was used for the control group. After course teaching was finished, selfefficacy and test scores of two classes were gathered and counted. Meanwhile, teaching effect contrast was conducted.

\section{Research tool}

After a large number of literatures were looked up, selfefficacy questionnaire adopted general self-efficacy scale (GSES) of Chinese version which was widely applied internationally and prepared by Schwarzer et al. [8]. The scale includes 10 items and involves self-confidence of individuals when they encounter setbacks or difficulties. The scale adopts Likert's 4-point scale form. Each item has 4 levels (i.e. 1-4 scores). The scale is a one- dimensional scale, and only total scale score is counted. The total score of 10 items divides 10 to gain the total score of the scale. All 10 items must be answered, or else the questionnaire is ineffective. The mean score subtracts standard deviation to get the critical score. Through the application of GSES of Chinese version for Chinese college students, it is found that Cronbach $\alpha$ coefficient is 0.87 ; retest reliability after about 10 days is 0.83 ; split-half reliability is 0.90 ; in terms of validity, the correlation of 10 items and total scale score is between 0.60 and 0.77 , which indicates the scale has good structure validity [8].

(1) Mode of control class

For the control class, the teacher followed traditional teaching method. The specific teaching mode is as follows: teaching organization and multimedia courseware were applied as the teaching carrier, and verbal explanation, PPT demonstration, question answering in classroom and task assignment were comprehensively applied for teaching.

\section{(2) Mode of experimental class}

For the experimental class, the teacher used distance learning system as the teaching carrier for routine teaching and examination, and took "valuation of bill quantity" in Construction Cost Engineering for example. Under the support of distance learning system, the teaching was carried out according to three stages.

Playing teaching video. In this stage, the teacher applied audio/video playing module in distance learning system to play the theory of "valuation of bill quantity" and practical calculation cases. In the specific teaching implementation, the teacher displays corresponding teaching video cases through recording, broadcasting and sharing functions of the system, and guided the students to observe. When students log in the teaching platform, the system can detect the network of student client and choose the most suitable learning mode for students according to the network condition so as to make sure every student can receive the learning resources the teacher provides.

Online learning and asking questions. After the teacher played the video, students were required to conduct online learning and several specific questions were sent to each student from the teacher terminal to the student client. Questions were selected from teaching resource library at random. Students carried out online independent learning according to these questions. In case of any doubt, students may send questions to the teacher through learning sharing module in the system, while the teacher needs to answer students' questions online.

Online examination and evaluation. When all students finished the study, the teacher utilized "online examination and evaluation module" in the distance learning system to send the uniform examination questions to students via the student client. Students were required to complete the examination and submit the answers within the specified time. After students finished the examination, the teacher clicked "answer checking" button, and students' examination score was generated at once. Meanwhile, the examination result was fed back to students. The result not just contained score, but also included analysis of wrong answers and standard answers. Under such feedback mode, students can cognize their mistakes. This greatly improves the effectiveness of examination feedback. (see figure 4 and figure 5) 


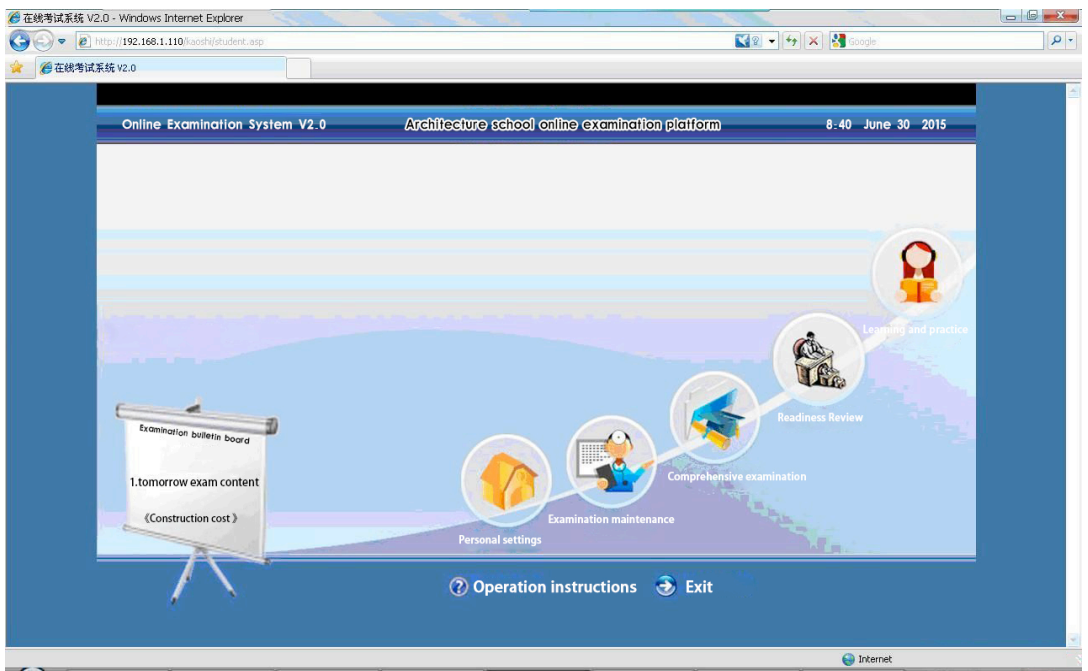

Figure 4. Implementation of offline distance learning system in teaching Construction Cost Engineering

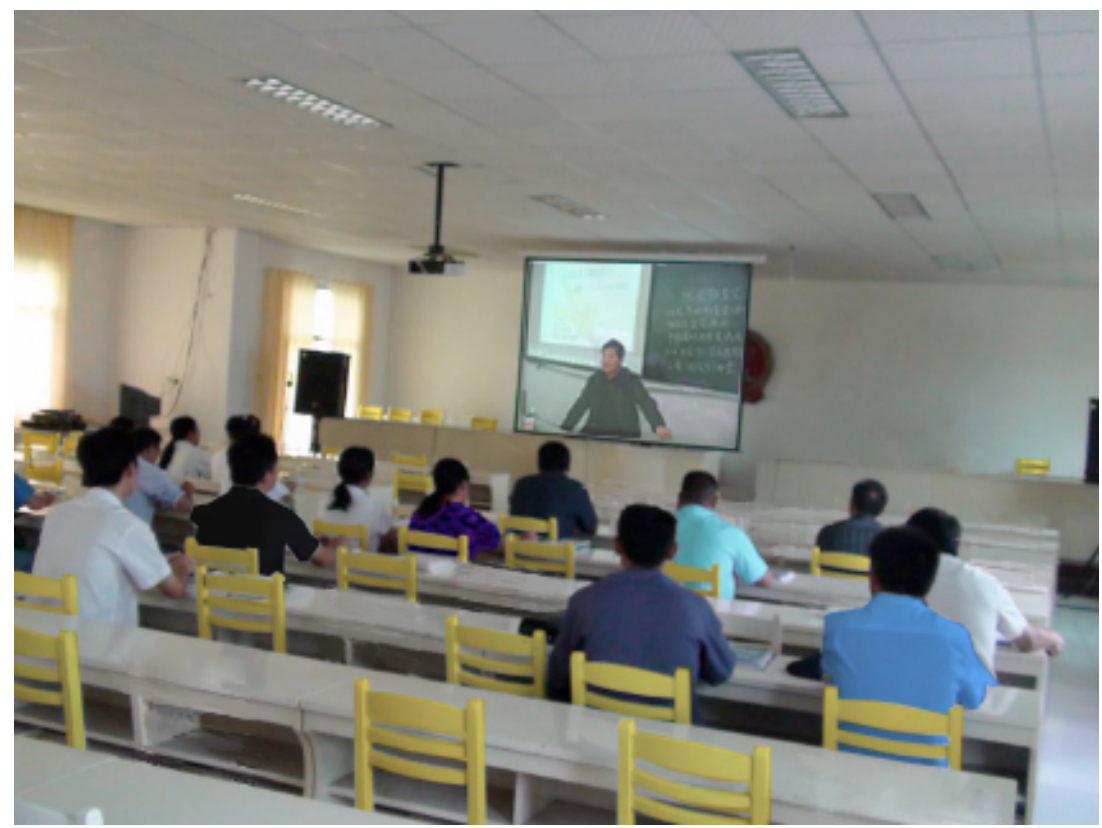

Figure 5. The scene real application of distance learning system in architecture

\section{TEACHING Result AND Discussion}

\section{A. Research tool}

After the teaching for 48 class hours, the teacher adopted questionnaire survey and theory test to count learning indexes of students in the two classes. The detailed statistical result is as Table I.

TABLE I.

COMPARISON OF LEARNING MOTIVATION AND SELF-EFFICACY OF STUDENTS In Two ClASSES BEFORE AND AFTER THE EXPERIMENT

\begin{tabular}{llll}
\hline & $\begin{array}{c}\text { Experimental } \\
\text { Group }\end{array}$ & $\begin{array}{c}\text { Control } \\
\text { Group }\end{array}$ & \multicolumn{1}{c}{ P } \\
\hline Before experimental & $14.88 \pm 3.11$ & $15.32 \pm 3.19$ & 0.488 \\
After experimental & $26.01 \pm 3.64^{\mathrm{a}}$ & $18.72 \pm 4.33^{\mathrm{b}}$ & $<0.0001$ \\
\hline
\end{tabular}

Note: different small letters in the same line mean significant difference, $\mathrm{P}<0.05$

As shown in Table I, in statistics of self-efficacy index, the students in the two classes have no significant differ- ence before the experiment $(\mathrm{P}>0.05)$. After the teaching experiment, the indexes of students in the experimental class are superior to those of students in the control class, and there is significant statistical difference $(\mathrm{P}<0.05)$. It thus can be seen that, offline learning system plays a significant role in promoting students' positive learning motivation and improving their self-efficacy. (see figure 6)

As shown in the Figure 6, the mean score of experimental class is 86.7 , while the mean score of control class is only 64.8. The mean score of experimental class is nearly 20 scores higher than that of control class. According to the deep interview and investigation, over $85 \%$ of students in experimental class express that the application of distance learning system can help them master more knowledge and communicate with the teacher in real time through the form of online distance learning. For the students who could not attend class in time for some personal causes, they could learn at home and participate in the examination via the computer. The fact proves that the efficiency is very high. 


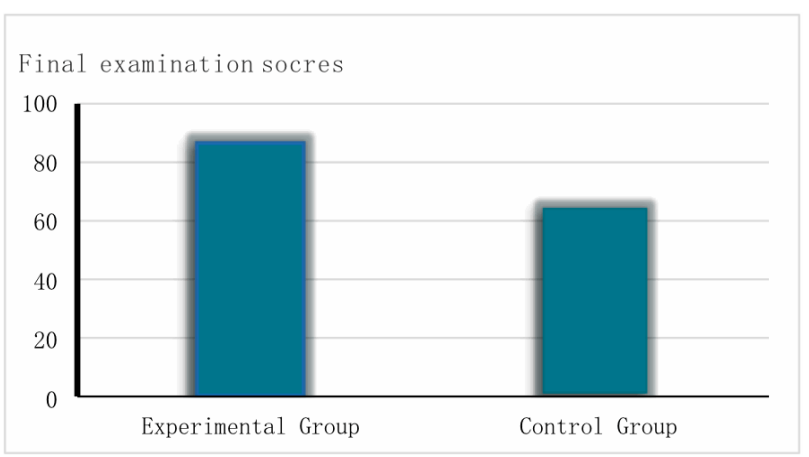

Figure 6. Statistical chart of final examination mean score of students in experimental class and control class

\section{B. Teaching discussion}

Construction Cost Engineering is a required course in college architectural engineering specialty. In the previous teaching, teachers usually adopted explanation method to teach, and course examination was based on paper test. The above teaching form is mature, but lacks innovation. Thus, it has no great advantages in the aspect of boosting students' learning initiative [9]. This paper studies and designs a distance learning system for Construction Cost Engineering. The system consists of audio/video recording and playing module, online learning and sharing module, online examination and evaluation module, network selfdetection module, module of automatic learning mode switchover etc. It is characterized by low flow and high intelligence and can satisfy distance teaching and examination demand of this course.

In the specific teaching, the teacher combines features of distance learning system to design "three-stage" teaching mode and guide students step by step through three processes: video playing - learning guidance - online examination. Besides, after teaching task of each class hour is finished, the teacher may utilize this system to examine students in time and feedback first-hand information about the wrong questions according to the examination situation so as to help students recognize their mistakes and construct firm and solid knowledge hierarchy of Construction Cost Engineering. The teaching practice verifies that this system has significant teaching assistance function for improving students' learning motivation and independent learning ability. Moreover, this system also actively assists students in boosting their examination scores. By applying online practice and examination functions of distance learning system, students can solve the difficult points in the study in time. In the whole learning process, they feel joyful and relaxed. Naturally, they enhance their examination scores.

\section{CONCLUSIONS}

This paper introduces the application of a distance learning system in Construction Cost Engineering in detail. The system has diversified functions such as flow detection, learning module conversion, online learning and examination. Teaching experiment comparison result also shows that compared with traditional teaching method, this system plays a significant role in improving teaching quality of Construction Cost Engineering. Therefore, this learning system should be widely popularized in other courses of architectural engineering specialty.

\section{ACKNOWLEDGEMENT}

\section{REFERENCES}

[1] Gamayunova O., Vatin N., Rechinsky A., Razinkina E., "Distance learning system Moodle for training of specialists in the field of civil engineering," Applied Mechanics and Materials, vol. 725, pp. 1611-1616, March 2015. http://dx.doi.org/10.4028/www.scien tific.net/AMM.725-726.1611

[2] Thoms B., Eryilmaz E., "How media choice affects learner interactions in distance learning classes," Computers \& Education, vol. 75, no. 3, pp. 112-126, June 2014. http://dx.doi.org/10.1016/ j.compedu.2014.02.002

[3] Rao S., Celeste S.M., "The Development and Evaluation of a Distance Learning System in Ophthalmology," Revista Brasileira De Educação Médica, vol. 37, no. 1, pp. 96-102, March 2013. http://dx.doi.org/10.1590/S0100-55022013000100014

[4] Sowan A.K., Jenkins L.S., "Designing, delivering and evaluating a distance learning nursing course responsive to students needs," International Journal of Medical Informatics, vol. 82, no. 6, pp. 553-64, June 2013. http://dx.doi.org/10.1016/j.ijmedinf.2013. $\underline{02.004}$

[5] Basioudis I.G., Lange P.D., Suwardy T, Wells, P., "Accounting students' perceptions of a Learning Management System: An international comparison," Accounting Research Journal, vol. 25, no. 2, pp. 72-86, April 2012. http://dx.doi.org/10.1108/103096 11211287279

[6] Salomon R., Wu Z., "Institutional distance and local isomorphism strategy," Journal of International Business Studies, vol. 43, no. 4, pp. 343-367, March 2012. http://dx.doi.org/10.1057/jibs.2012.3

[7] Duncan I., Miller A., Jiang S., "A taxonomy of virtual worlds usage in education," British Journal of Educational Technology, vol. 43, no. 6, pp. 949-964, June 2012. http://dx.doi.org/10.1111/ j.1467-8535.2011.01263.X

[8] Zhang J.X., Schwarzer R., "Measuring optimistic self-beliefs: A Chinese adaptation of the General Self-efficacy Seale," Psychologia, vol. 38, no. 3, pp. 174-181, September 1995.

[9] Gu W.H., Bao X.Y., Hao W., "Research and Practice on Construction of Project Cost Curriculum Group," Journal of Architectural Education in Institutions of Higher Learning, vol. 24, no. 3, pp. 27-31, June 2015.

\section{AUTHORS}

Yuqiao YANG (corresponding author) is a Teacher of School of Architecture, Chang'an University, Xi'an 710061, Shanxi, China. His research interests include Internet of Things Technology and Micro-video Course. (yangyuqiao22@yeah.net)

Kanhua YU is an Associate profession of School of Architecture, Chang'an University, Xi'an 710061, Shanxi, China. His research interests include City Planning and Micro-video Course. (yukanhua@yeah.net)

This work was supported by National Natural Science Foundation of China (51378067), Social science fund of Shaanxi Province (213041140109) and Basic scientific research projects of Central University (310841155033) for this work. Submitted 25 April 2016. Published as resubmitted by the authors 24 June 2016. 